\title{
Web-based Multi-criteria Spatial Decision Support System for the Assessment of Environmental Sustainability of Dairy Farms
}

\author{
Sandra Silva $\left({ }^{\mathrm{a} b}\right)$, Luís Alçada-Almeida $\left({ }^{\mathrm{b} c}\right)$, Luís C. Dias $\left({ }^{\mathrm{b} c}\right)$
}

(a ) Polytechnic Institute of Viana do Castelo, Praça General Barbosa 4900-347, Viana do Castelo, Portugal

Tel.: +351258 809 610; Fax: +351258 829 065; E-mail:sandrasilva@esa.ipvc.pt

(b ) Institute for Systems Engineering and Computers, Rua Antero de Quental, No199, 3000 - 033 Coimbra, Portugal.

(c) Faculty of Economics, University Coimbra, Av. Dias da Silva, 165, 3004-

512 Coimbra, Portugal

This is a PDF file of an unedited manuscript that has been accepted for publication in Computers and Electronics in Agriculture.

The manuscript will undergo copyediting, typesetting, and review of the resulting proof before it is published in its final form. Please note that during the production process errors may be discovered which could affect the content, and all legal disclaimers that apply to the journal pertain. The final version will be available at:

https://doi.org/10.1016/j.compag.2014.06.009

\begin{abstract}
The assessment of the environmental sustainability of agricultural infrastructures involves the use of multiple evaluation criteria and the analysis of geographical information. A Geographic Information System (GIS) is a computer system capable of assembling, storing, analyzing, and displaying geographically referenced information. However, the GIS technology still suffers from several shortcomings due in large part to a lack of capable analytical capacity of supporting spatial decision problems. The most
\end{abstract}


common solution for GIS to evolve into an effective tool for decision support is to couple them with operational research tools and in particular Multicriteria Decision Aid (MCDA). Due to the technological advances in the field of information systems, there is a great need to research how to integrate GIS, MCDA, the Internet, modeling and databases aiming at creating Web Multicriteria Spatial Decision Support Systems (Web MC-SDSS). A Web MC-SDSS methodological framework is proposed for a fully integrated system of GIS and a specific MCDA method - ELECTRE TRI, through the construction of a Macro written in Visual Basic for Applications (VBA) in ArcGIS software. This macro interacts with a Web Algorithm Server for computing MCDA results. The developed Web MC-SDSS, named ELECTRE TRI in ArcGIS, is applied on a case study analysing the environmental sustainability of dairy farms in the EntreDouro-e-Minho (EDM) Region.

Keywords: Multicriteria Decision Aid, Geographic Information Systems, Spatial Decision Support Systems, Web MCDA Algorithm Server, ELECTRE TRI, Sustainability Analysis.

\section{Introduction}

Spatial decision problems in agriculture and other areas often require that a large number of alternatives are evaluated based on multiple criteria. Geographic Information Systems (GIS) are a powerful tool for analysing spatial data and establishing a process for decision support. Multicriteria Decision Aid (MCDA) methods can facilitate decision making in situations where several solutions are available, various criteria have to be taken into account and decision makers are in conflict (Dias et al., 2002). 
The combination of spatial analysis with MCDA has allowed the creation of Multicriteria Spatial Decision Support Systems (MC-SDSS), whose aim is to formulate and support spatial decision problems. This process involves the use of geographical data, the decision maker's (DM) preferences and the manipulation of the data and preferences according to specified decision rules (Sharifi and Retsios, 2004; Malczewski, 2006).

The integration of MCDA tools in GIS has been used in several projects and studies from different areas over the last twenty years as evidenced by the survey by Malczewski (2006). One of the most remarkable features of the GIS-MCDA approaches is the wide range of decision and management situations in which they have been applied, such as environment/ecology, transportation, urban/regional planning, waste management, hydrology, agriculture, forestry, geology, or site selection. Among some works, we highlight the works of Joerin et al. (2001), Gilliams et al. (2005), Aydin et al. (2010), Marinoni (2004), Eldrandaly et al. (2005), Boroushaki and Malczewski (2008), Vogel (2008), applied in different areas. In these applications the flexibility in representing and analysing spatial information is particularly pertinent as it is assumed that about $80 \%$ of the data used by decision-maker (DM) in decision processes are geographically interrelated (Worrall, 1991).

Current developments in computational speed, storage volumes, World Wide Web (WWW) global access and software integrated development environments (IDE) provide opportunities to develop SDSS exploring both the advantage of information dissemination for DMs and the integration of GIS-MCDA. One of the greatest benefits of using Web Services in spatial decision making is the potential to overcome limited resources in terms of time, data and communication. The web enabled GIS facilitates 
decision making and serves as a gateway for decision makers and general users to access the system conveniently and effectively.

The typical Web SDSS is a web-based GIS, where GIS information implemented in World Wide Web environment (Google Maps, and others) and Open Source GIS software is used, where MCDA methods are integrated. In this paper we develop a distinct Web SDSS: a web-based Multicriteria Decision Aid in GIS software. This Web MC-SDSS integrates an MCDA method which is solved by a Web-based Algorithms Server that contains various MCDA tools, according to a clearly defined communication protocol. This integration uses the ArcGIS commercial software as user front-end. The Web MC-SDSS interface created named ELECTRE TRI in ArcGIS is a full integration of the MCDA outranking ELECTRE TRI method and GIS through the construction of a macro written in Visual Basic for Applications (VBA) programmed in ArcGIS 9.3 of ESRI. This interface is capable of: 1) providing mechanisms for the input of spatial data; 2) allowing representation of the spatial relations and structures; 3) applying the analytical techniques of spatial and geographical analysis; 4) providing output in a variety of spatial forms, including maps; 5) performing sensitivity analysis.

The resulting Web MC-SDSS was developed to address a real-world case study of decision analysis to assess environmental sustainability of dairy farms in Portuguese region, although it can be applied to other studies in different areas. Namely, the system was used to classify 1705 dairy farms in the Entre-Douro-e-Minho (EDM) Region according to environmental sustainability criteria. Seven environmental criteria were defined by three experts from Environmental and Zoo-technic areas. The classification allows determining which farms are sustainable from an environmental perspective, which ones are not sustainable, and, as an intermediate category, which ones are barely sustainable. 
This paper is divided into five sections. Sections 2 e 3 offers a brief literature review regarding the Multicriteria Spatial Decision Support Systems, characterizing their types and directions of integration of MCDA and GIS as well as integrations available in GIS software and the development of Web MC-SDSS. In section 4, the case study with description of problem and the criteria involved as well as the characterization of the chosen method, ELECTRE TRI, is presented. In section 5, we introduce the MC-SDSS approach, enhancing the type of developed integration of GISMCDA, as well as the created architecture of MC-SDSS. Finally, in section 6 the conclusions that have been drawn from the study are presented encouraging the opportunities for expanding the work.

\section{Multicriteria Spatial Decision Support Systems}

Finlay (1994) defines a DSS broadly as "a computer-based system that aids the process of decision making." The basic idea of DSS is to provide a computer-based framework that integrates database management systems with analytical models and graphics to improve the decision-making process. SDSS are a class of computer systems in which the technologies of both GIS and DSS are applied to aid decision makers with problems that have a spatial dimension (Walsh, 1992).

GIS and MCDA are currently the two most common decision support tools employed to solve spatial decision-making problems. Some authors consider GIS itself as a form of spatial decision support system (SDSS). However, GIS is widely recognised as a computer based system that combines spatial database management, geo-statistical analysis and mapping but not more than that (Laaribi et al., 1996; Van 
der Meulen, 1992; Malczewski, 1999). GIS can provide the decision makers with spatial information but it does not provide any type of preference modelling for decision support. Conventional MCDA techniques are mostly non spatial in nature and are subject to the assumption that the area under consideration is spatially homogeneous. This assumption makes such techniques unrealistic as, in many cases, performance criteria vary across the space.

In recent years, to avoid the limitations of each system (GIS and MCDA) in the area of spatial decision support, the idea of integrating GIS with different MCDA modelling has emerged in different areas of application such as: land suitability (Marinoni, 2004, Santé-Riveira et al.,2008), route location (Jankowski and Richard, 1994), risk-based in natural hazards (Chen et al., 2001), bank branch closures (Zhao et al., 2001), land management (Joerin and Musy, 2000), and location of undesirable facilities (Ferretti, 2011).

Abel et al. (1994) have identified three major advantages of integration: enhancing the evolution of GIS, improving the desired level of usability, and enriching approaches to problem solving. Therefore, both GIS and MCDA can be made more useful and complete through their integration and the effort to combine the strengths of these technologies would be mutually beneficial to both communities as well as those participating in decision-making processes (Parks, 1993). The integration of decision making techniques designed to handle multicriteria problems within GIS can provide users with a valuable extension of the functionality of GIS (Carver, 1991; Goodchild, 1992).

Multicriteria Spatial Decision Support Systems (MC-SDSS) integrate GIS based data processing and analysis techniques as well as MCDA. MC-SDSS provides a consistent framework that allows combining spatial data and decision maker's 
preferences according to a selected decision rule. MC-SDSS tools offer unique capabilities for automating, managing and analysing spatial decision problems with large sets of feasible alternatives and multiple conflicting and incommensurate evaluation criteria.

The way the two components are integrated depends on (Ascough et al, 2002): 1) the MCDA models incorporated into the MC-SDSS system (e.g., multiobjective versus multiattribute decision analysis techniques; 2) the decision making philosophy behind the design strategy (e.g., a system for supporting a single-user versus collaborative decision making); and 3) specific types of decision problems concerned (e.g. environmental problems, planning problems, location, etc).

Operationally, the integrated GIS-MCDA approach starts with the problem identification, where the capabilities of the GIS are used to define the set of spatial alternatives and the set of criteria. Then, the overlay analysis procedures are used in order to reduce an initially large set of alternatives into a small number of alternatives which are easily evaluated by using a multicriteria model. Finally, the drawing and presenting capabilities of the GIS are used to present results (Chakhar and Martel, 2003). There is a large literature on GIS-MCDA integration available (see Malczewski, 2006).

MC-SDSS can be classified according to the extent of integration and the direction of integration of GIS and MCDA. Integration indicates the degree to which functions of software can be controlled directly by one another. It refers to the physical and logical connection between the software packages in the system. There are four possible modes of physical integration of GIS and multicriteria analysis tools (Goodchild, 1992; Chakhar and Martel, 2003; Jankowski, 1995; Malczewski, 1999, 2006 and 2010, Chakhar and Mousseau, 2007): (i) no integration, (ii) loose integration, 
(iii) tight integration, and (iv) full integration. The first mode was dominant until the late 80 's, when GIS and multicriteria analysis were used independently, without any connection between them. The other three modes represent increasing levels of complexity and efficiency of integration (see Figure 1).

The loose integration approach (also called MCDA-GIS indirect integration in Chakhar and Martel, 1993) facilitates the integration of GIS and MCDA techniques using a file exchange mechanism, named intermediate system (Jankowski, 1995; Malczewski, 1999). It involves running MCDA models outside a GIS, using the latter as a source of data and as a means of displaying the results. Separate tasks are performed in either system (GIS and multicriteria modeling system). The loose integration architecture is based on linking three modules (GIS module, multicriteria technique module and file exchange module), as seen in Figure 1 (a).

The tight integration approach (also called Built-in MCDA-GIS models in Chakhar and Martel, 1993) are based on a single data or model manager and a common user interface (Jankowski, 1995). Thus, the two systems share not only the communication files but also a common user interface (Figure 1 (b)). In this type of integration, a particular multicriteria analysis method is directly added to the GIS software. The multicriteria analysis method is an integrated but autonomous part with its own database.

The full integration (also called Complete MCDA-GIS integration in Chakhar and Martel, 1993) yields itself to a complete GIS-multicriteria analysis integrated system that has a unique interface and a unique database (Figure 1 (c)). Here, the multicriteria analysis method is activated directly from the GIS interface as any GIS basic function. The GIS database is extended so as to support both the geographical and descriptive data, on the one hand, and the parameters required for the multicriteria evaluation 
techniques (Chakhar and Mousseau, 2007) on the other. This approach requires a high level of knowledge of the GIS in question and considerable programming skills. "Macro language" in ArcGIS software facilities available in a proprietary GIS are used to couple with MCDA models. To provide a full range of decision support functionalities the GIS system needs to be customized.

Figure 1 goes about here

MC-SDSS can also be classified in terms of the direction of integration. Four categories of approaches can be identified (Malczewski, 2006 and 2010; Chakhar and Mousseau, 2007): (i) one-direction integration with GIS as main software, (ii) onedirection integration with MCDA tool as main software, (iii) bi-directional integration, and (iv) dynamic integration. One-direction integration provides a mechanism for importing/exporting information via a single flow that originates either in the GIS or MCDA software. In the bi-directional integration approach the flow of data/information can originate and end in the GIS and MCDA modules. While bi-directional integration involves one-time flow of information, dynamic integration allows for a flexible moving of information back and forth between the GIS and MCDA modules according to the user's needs (Malczewski, 2006).

Some MCDA modules were developed in the commercial and open source GIS software, in the 90`s. Loose integration is the first usage that has been made out of GIS and MCDA capable systems. In the last decade efforts have focused on the development of more comprehensive solutions in order to couple MCDA and GIS tools in a single interface. These efforts were encouraged by the means provided for preparing, compiling and running macros or plug-ins on development platforms, which allow 
writing application programs with programming languages such as Visual Basic, C, C++, Python and others (Sugumaran and Degroote, 2011). This approach enables the GIS evaluation functions to facilitate the spatial decision making with multiple criteria. The functions include: generation of decision table, elicitation of decision-maker's preferences, selection of aggregation function, and sensitivity analysis (Jankowski, 1995).

The conceptual idea of combining GIS-MCDA is based on the use of GIS capacities to prepare a suitable platform for the use of MCDA methods. Although numerous applications of GIS-based MCDA methods have been reported in the literature, MCDA components are incorporated in only a few GIS programs (e.g. ARCGIS, IDRISI, ILWIS, QUANTUM, DECERNS, GRASS, Common GIS, etc.,) at the present time.

A considerable number of decision rules have been proposed in MCDA-GIS integration. The most common are Weight Summation/Boolean Overlay, Ideal/Reference Point, Analytical Hierarchy Process (AHP) and Outranking methods (ELECTRE and PROMETHEE) (Malczewski, 2006). As for the ELECTRE TRI method and their integration into GIS software, we can cite the following examples: Sobrie $(2011,2013)$ developed a plug-in to implement the ELECTRE TRI algorithm using Python programing language in QUANTUM software. This interface allows the interaction between selection of alternatives, determining the parameters for the ELECTRE TRI and visualization of the results through a generation of a decision map out of a multicriteria map, i.e. it is defined as a full integration GIS-MCDA interface (Sobrie and Pirlot, 2012). Boggia et al. (2011) implemented a module named r.mcda.electre for MCDA in GRASS software, written in C language. Chakhar and Mousseau (2009) have developed a prototype created with the ArcGIS and the 
ELECTRE TRI method, using VBA. The prototype allows creating criteria maps, inferring preference parameters for ELECTRE TRI, assigning spatial unit categories, and generating decision alternatives based on a planar subdivision. Mendas and Delali (2012) incorporate the ELECTRE TRI in ArcGIS to assessing land suitability for agriculture.

The use of MCDA methods to assess the sustainability of agriculture is still scarce. Raju el al. (2000) implements a multi-criteria analysis for sustainable water resources planning using ELECTRE TRI and other MCDA techniques. Antunes et al. (2011) present the development of a participatory multicriteria analysis process using AHP and SMCE (Social Multi-Criteria Evaluation) for the evaluation of irrigation management alternatives. Van Calker et al. (2006) apply MAUT for an economic, social and ecological assessment of sustainability, to Dutch dairy farms. Dantsis et al. (2010) use MAVT to evaluate and compare the level of sustainability of farms in two Greek regions. Gómez-Limón and Riesco (2009) and Santos (2011) apply the AHP aggregation method in the evaluation of agricultural sustainability. Lebacq et al. (2013) review typologies of sustainability indicators that have been developed at the farm level and present a case study to help users to select a set of indicators. The application of the ELECTRE TRI method developed in this research to assess dairy farms is a novelty, further with the integration of this method with GIS.

\section{Web-based MC-SDSS}

Rapid growth of the Internet over the past decade has opened up new ways to supply data, tools, models, and other information to potential users. The Internet could become one of the most important instruments for the process of spatial decision making because of its distributed, time-independent and license free nature. It provides 
decision makers with the opportunity to gather information and it provides an ideal platform to increase the use and accessibility of spatial data.

Over the last fifteen years or so, a considerable research effort has been made to integrate GIS capabilities and MCDA methods in the context of the Internet (Menegolo and Peckham, 1996; Carver, 1999; Zhu and Dale, 2001; Rinner and Malczewski 2002, Sikder and Gangopadhyay, 2002; Dragićević, 2004; Hall and Leahy, 2006; Karnatak et al., 2007; Rao et al., 2007; Simão et al., 2009, Boroushaki and Malczewski, 2010). Rinner and Malczewski (2002) suggest that most of the first generation Web GISMCDA applications focused on the technical aspects of GIS and MCDA integration to address the analytical structure of spatial problems (Boroushaki and Malczewski, 2010). Most of the second generation Web GIS-MCDA applications addressed the shortcomings of the analytical structure by providing more comprehensive and sophisticated analytical modules (Rinner and Malczewski 2002). Rinner (2003) summarizes research on Web-based spatial decision support systems, with various examples of tools and applications.

The inclusion of MCDA techniques tools in GIS software can be accomplished in two ways: (i) by programming a method similar to the work done on MCDA techniques insertion in the GIS software; (ii) or, through the use of algorithms of MCDA methods already developed in a server, which requires only programming for the definition of the parameters associated with the method(s) chosen. The latter way facilitates code integration in client applications by providing data input/output communication protocols for each of the functionalities offered. In this work, we opted for the second way of inclusion of MCDA techniques leveraging a Web Algorithms Server. The proposed solution consists of installing an array of algorithm servers, acting as a unique high-performance computer, linked to a worldwide web node and providing execution 
time to the authorized users. The algorithm server is based on a high level interface module that automatically generates inputs for different MCDA algorithms, according to user objectives and according to user inputs, not requiring any programming or specific algorithm knowledge.

There are few Web-MCDA services available. A good example is the DecisionDeck Project (http://www.decision-deck.org/) which developed an open-source generic Multiple Criteria Decision Analysis software platform composed of various modular components. In this work, the Web Algorithms Server is a MCDA web-service created by Kreation Research http://kreation.dec.uc.pt/index.html. The following MCDA methods have already been implemented in this Algorithms Server: ELECTRE family methods, AHP, TOPSIS, Simple Weighted Method and General Use Mixed Integer Linear Programming Solver. The typical end-user of this platform is an MCDA researcher, an MCDA consultant or a teacher in an academic institution.

The implementation of Web-MCDA in GIS (through an external algorithm server) has the following advantages:

- the availability of different MCDA algorithms;

- the possibility of execution of various algorithms on the same problem;

- it offers automatically to the user community, through the web, algorithm improvements, error corrections, and new functionalities that require no action from the algorithm server clients;

- it rationalizes investments in hardware, avoiding the acquisition of expensive high performance machines and fare fast in obtained results;

- it allows the efficient dimensioning of hardware and respective features, in order to optimize processing loads; 
- the control access to data and GIS software functions and immediate visualization of results.

This paper discusses an approach for developing a Web-based Multicriteria Decision Aid (Web-MCDA) in commercial GIS software: ArcGIS version 9.3. The approach focuses on a framework for building Web-based MC-SDSS for analysing and processing spatial data for spatial decision support using a Web Algorithm Server contains various MCDA rules that enable the user to select the appropriate type of model to use for a particular task and perform sensitivity analysis. The Web MC-SDSS implemented provides an enrichment of capacities of the GIS software using various methods MCDA available via web service and provides an ideal platform for nonexperts to access the power and benefits of MCDA and GIS tools. In this study we apply the Web MC-SDSS to a spatial multicriteria decision problem: the environmental sustainability classification of dairy farms in a Portuguese Region, using Web ELECTRE TRI MCDA method in ArcGIS software.

\section{Case Study: Environmental Sustainability Classification of Dairy Farms}

\subsection{Description of the Problem and Case Study Area}

In recent years the pressure of external markets and agrarian policies, directives for the protection and animal welfare as well as environmental quality and food security have influenced the activity and the sustainability of some Dairy Farms. Environmental sustainability involves making decisions and taking actions that are in the interests of "maintenance of natural capital" (Goodland, 1995), with particular emphasis on 
preserving of human life and ecological systems. The preservation of ecosystems in order to promote their maintenance and welfare of the population and animals, coupled with the sustainability of livestock production, demand a concerted action in order to perform a set of analyses and build a multicriteria spatial decision support tool in order to reflect upon the balance of different points of view taking into account multiple criteria to capture the environmental aspects involved. This study aims at assessing the environmental sustainability of this activity in the Entre-Douro-e-Minho (EDM) Region, which is the main Portuguese milk production area. The EDM area is characterized as the Primary Dairy Basin in the EDM Region located in the Northwest Region of Portugal (Figure 2) and it consists of 10 counties: Viana do Castelo, Barcelos, Esposende, Póvoa de Varzim, Vila Nova de Famalicão, Vila do Conde, Santo Tirso, Trofa, Matosinhos and Maia. In this region there are 1705 dairy farms which are the subject of this study. They are particularly distributed across the region of Vila do

Conde, Póvoa de Varzim, Vila Nova de Famalicão and Barcelos (Figure 2). The total area of farms in the study measures 20,331 hectares (ha) and the average physical dimension of the farms is 12 ha. There are 1705 dairy farms, with an average number of 61 dairy animals per farm.

Figure 2 goes about here

\subsection{Definition of Environmental Criteria}

Three experts from Environmental, Agro-Economic and Zoo-technic areas are involved in the definition of the environmental criteria. In defining the criteria the experts take into account the new rules for licensing bovine activity (Portuguese Decree-Law 202/2005 that regulates the issue of managing different livestock 
effluents), the Code of Good Agricultural Practices, Manual Fertilization of crops and Water Act, and European legislation and recommendations. Data for these environmental criteria were obtained from the survey developed during the implementation of the EDM Primary Dairy Basin Plan (POBLPEMD, 2007). The environmental criteria are summarized in Table 1.

Table 1 goes about here

An important factor is the farms' compliance with legal requirements whether environmental or food related, or those created for the protection of soil and water. These requirements intend to preclude farms that, due to scarce resources and capabilities, and misuse of methods and equipment, lead to contamination of crops and waterways and production of unpleasant odors, among other problems.

Consumers and society in general have forced the introduction of new attitudes with regard to questions of dairy production in particular, such as animal welfare and traceability, environmental impact and food safety. The costs associated with this activity are significant as the contribution to the greenhouse effect has to be mitigated through trading emissions or carbon taxes.

\subsection{Multicriteria method implementation: ELECTRE TRI}

To assess the Sustainability Classification of Dairy Farms, based on GIS and MCDA methods integration, we used a particular Outranking Method, ELECTRE TRI (Yu, 1992). The outranking approach is based on pairwise comparisons between potential alternatives (also known as actions) using an outranking relation (Roy, 1996): one alternative outranks another if the former is considered "not worse than" ("at least as good as") the latter. Outranking methods cope well with spatial decision problems since they: (i) permit to consider qualitative evaluation criteria (in addition to quantitative ones); (ii) permit to consider evaluation criteria with heterogeneous scales 
where the coding into one common scale is very difficult or artificial; (iii) avoid the compensation between evaluation criteria; and (iv) require fewer amount of information from the decision maker (DM) (Chakhar and Mousseau, 2009).

For this study, the outranking approach seemed more appropriate because, although it is less familiar to decision makers (compared to a weighted sum) and it requires more configuration parameters, it presents the following two advantages: first of all, as a multicriteria assignment method, it sorts alternatives (dairy farms) by preferenceordered categories. Indeed, in classification of dairy farms, where various environmental aspects are at stake, it is often important to use known standards (reference profiles defined in legislation) to define various categories of sustainability. This requires capability of evaluating each farm in absolute terms, not just in comparison with other peers, as well as the need to include evaluation aspects expressed in different units, using any type of scales (including qualitative). The classification of a dairy farm does not depend on the other dairy farm being evaluated, ie, there is no need to compare the farms among themselves, it is only necessary to compare the farms to predefined categories. The second advantage is related to the fact that ELECTRE family multicriteria methods refuse the possibility of total compensation between the alternative's performances on the criteria. Thus it prevents that a farm with very good performance on some criterion compensates a very poor performance on another criterion and achieves the best category despite that major weakness.

The ELECTRE TRI method provides a complete sorting of the alternatives of the set A into two or more ordered categories $C_{i}, i=1, \ldots, k$, where $C_{1}$ is the worst (less desirable) category and $C_{k}$ the best one. In order to define the categories ELECTRE TRI uses some reference alternatives (reference profiles) $b_{i}, i=1, \ldots, k-1$, which are usually different from the alternatives in A (i.e., category boundaries can be real or hypothetical alternatives). Each reference profile $b_{i}$ is simultaneously the upper bound of category $C_{i}$ and the lower bound of category $C_{i+1}$. The assignment of each alternative $a \epsilon A$ to a category $C_{i}$ is done by comparing its value in each criterion to the reference profiles. In this work, the set of alternatives are dairy farms and the predefined categories consist of three sustainability levels, defined by the expert: Not Sustainable (Category 1), Barely Sustainable (Category 2) and Environmentally Sustainable (Category 3).

Two assignment procedures, optimistic and pessimistic, are available to analyse the way alternative a compares to the profiles, in order to determine its category. The 
pessimistic procedure aims at assigning each alternative to the highest category for which that alternative outranks its lower bound in the reference profile: a belongs to $C_{1}$ if it does not outrank $b_{1}$, it belongs to $C_{2}$ if it outranks $b_{1}$ but it does not outrank $b_{2}$, and so on. The optimistic procedure assigns each alternative, a, to the lowest category for which the lower profile $b_{i}$ is strictly preferred to a. The result of these two assignment procedures differs when the alternative a is incomparable with at least one profile $b_{i}$ (Yu, 1992).

The detailed algorithm and concepts of this method can be found, for instance in: Yu (1992), Roy and Bouyssou (1993), Mousseau and Dias (2004), and Figueira et al. (2005, 2010). This approach requires the decision makers (DMs) to set some parameters in order to build the outranking relation that evaluates the alternatives. These parameters can be divided into preference parameters (relative importance coefficients of criteria or weights, thresholds and profiles) and the technical parameter (cutting level). Taking into account the inaccuracies and uncertainties in the performances of the alternatives, thresholds of indifference and preference were defined for each criterion. The indifference threshold $\left(q_{j}\right)$ indicates how much a value may differ from the profile's value so that both be treated the same way. The preference threshold $\left(p_{j}\right)$ indicates a difference of values significant enough to consider an alternative strictly preferred relatively to another on the respective criterion. The set of weight-importance coefficients $\left(w_{j}\right)$ (such that $\left.\sum_{j} w_{j}=1\right)$ is used in the concordance test when computing the relative importance of the coalitions of criteria being in favor of the assertion " $a$ outranks $b_{i}$ ". The set of veto thresholds $\left(v_{j}\right)$ is used in the discordance test; if for one criterion the alternative is worse than the a category's reference profile by a difference reaching or exceeding the veto threshold, the alternative will not outrank the profile, no matter what the other values of the criteria for that alternative are. For the classification procedure it was also necessary to define a "cutting level" $(\lambda \in[0.5,1])$, indicating the percentage of the criteria (considering their weights) that must be in accordance in order to assign an alternative to a specific category.

In this particular case study, the expert defined the parameters involved (see Figure 5). This method required posing various questions to the expert to define the different preference parameters. 


\section{A Web Multicriteria Spatial Decision Support System Approach: Implementation of ELECTRE TRI in ArcGIS}

\subsection{Architecture of Web MC-SDSS}

The Web MC-SDSS developed has been characterized as a full and dynamic GISMCDA integration mode, so the general structure developed is based on Figure 1 (c), and further detailed in Figure 3. The interface is totally integrated in a single system as any new GIS function, making use a server algorithm for execution of the MCDA method (whose code is already pre-programmed) via the Internet. The users can access a web based front-end that acts as a high level interface to the MCDA methods included in the server.

Figure 3 goes about here

The basic structure of developed MC-SDSS interface is composed by seven main components:

User interface: An interaction display component, which provides a dialogue environment between the system and the users.

Standard GIS Functions (or geographical data management and analysis tools): A data viewer component which permits users to access GIS data and information directly from their spatial locations.

Spatial Data Base Management System: is used specially to manage and store the spatial data.

Geographic Data Base: is the repository for the spatial and descriptive data. 
Multicriteria evaluation functions (or MCDA models): a data selection/criterion weighting component, which allows users to select and weight a set of constraint and criterion maps.

Model Management System: the role of this component is to manage the different MCDA models. It contains different MCDA methods and permits the user to select an appropriate model or function for the problem under study.

Interactive Spatial Decision Map: uses map-based structures in order to provide an on-line visualization of the decision space, enabling the decision-maker(s) to appreciate visually how the results are affected when one or several decision parameters change.

This Web MC-SDSS works as follows: the user must register on the web-MCDA to access the algorithms server that contains different MCDA methods. After this, the user can have direct access to the resolution of a particular MCDA method by an input/output file sharing scheme using a web-based communication protocol between the interface developed and the server. Finally, using ArcGIS software (or other GIS integrated development environment) users can develop, and imbed in applications, procedures that establish automatic communications with the algorithm server, allowing to fully integrate their functionalities as if they belonged to application code.

Spatial and descriptive data, associated to environmental criteria in study, are entered in the Geographic Data Base of ArcGIS. This information is aggregated to geographic location (coordinates) of each alternative in analysis and is available in Geographic Data Base. From this moment, it is possible to store and manage the spatial data via Spatial Data Base Management System. In addition, the user has access to the set of tools, which are available in full-fledged GIS systems, the GIS Standard 
Functions. Typically, it includes techniques and methods for exploratory data analysis, generating criterion maps, and alternative spatial patterns (Malczewski, 2010).

The fundamental consideration in designing this MC-SDSS is the compatibility of the data constructed between the GIS model and the MCDA modeling system. In this end, a grid based spatial construct provides a convenient data model for storing attribute data in tabular format (decision matrix) that can serve as data input for the multicriteria modeling.

Multicriteria evaluation functions include tools for preference modeling, and multicriteria decision rules for evaluating a set of alternatives and performing sensitivity analysis (Malczewski, 2010). The MCDA tool was developed and integrated in the GIS through Macros. ArcGIS provides Macros that can be used to develop external programs/scripts as incorporated into it, using programming languages such as VBA. The user enters the parameter values associated with a particular MCDA method, in this case ELECTRE TRI, through the User interface (Macro). This Macro includes a generation of decision tables, elicitation of decision-maker's preferences, selection of aggregation functions among the Server's MCDA Algorithms and visualization of the results in maps.

The algorithm server (Model Management System) runs discrete methods by reading an input file in format required by protocol communication. This MCDA method is applied and an output file is created, in the same format, with the results that can be presented in different ways depending on the associated method.

The interface designed in the developed MC-SDSS provides a dialogue environment between system and users. The development of the MC-SDDS is guided by the principle of "user friendliness" because dealing with spatial decision-making, with huge quantity of data and models may prove to be complex for users. For decision 
makers, the interface of the system is the only access point to the database and models. The user interface needs to represent two spaces: objective space and map space.

Details of the MC-SDSS architecture and the technical aspects involved in its development are explained in detail in next section, with description of ELECTRE TRI in ArcGIS.

\subsection{Macro-description of ELECTRE TRI in ArcGIS}

ArcGIS is based on a common library of shared GIS software components called ArcObjects. ArcObjects are sets of computer objects specifically designed for programming with ArcGIS Desktop applications. ArcGIS includes an integrated macro development environment, through Visual Basic for Applications (VBA) programming language that permits extending their functionality. VBA, a simplified version of visual basic (VB), is one of many object-oriented programming languages. There are three main reasons for us to develop a program in a VBA macro in the ArcGIS environment. (1) VBA macros in ArcGIS applications can use the ArcGIS functionality to its full extent; (2) VBA macros can take advantage of global ArcGIS variables; (3) creating, testing and debugging macros in the ArcGIS Visual Basic editor are the same as in the VB development environment (Marinoni, 2004).

The developed Macro interface, named "ELECTRE TRI in ArcGIS", is a powerful visual spatial decision-aid tool, where the user interacts with a representation very similar to typical database dialogue interfaces, indicates his/her preferences, manipulates spatial objects and modifies/changes their descriptive attributes, adds/deletes other spatial objects, appreciates the effects of any modification affecting any preference parameter, etc. 
The interface is characterized by four modules. Each module of the proposed conceptual framework is interconnected and provides a group of functionally related capabilities; therefore the system must be a holistic and seamless environment.

I. Criteria and Data Information - Problem is set, input layer is defined, criteria are specified and a spatial based table is constructed, that provides a convenient data model for visualization of the data attributed in tabular format (decision matrix). Figure 4 shows this first module.

Figure 4 goes about here

The Web MC-SDSS developed is applied on a case study of sustainability of dairy farms in the EDM Region. All dairy farms are to be sorted into three categories: Not Sustainable (Category 1), Barely Sustainable (Category 2) and Environmentally Sustainable (Category 3). In this module, the user chooses the Input Layer within the current map document of ArcGIS and chooses the criteria involved in this layer. Next, the user can visualize the values associated with each criterion (decision matrix) and define the objective for each of them. In "Objective" the user selects the sense of increasing preference on each criterion, i.e. whether it is a criterion that has to be maximized or minimized.

II. Parameters of ELECTRE TRI - Sets the parameters of ELECTRE TRI, defining the reference profiles, thresholds (indifference, preference and veto), weights and cutting level, that are validate for macro developed. After defining the parameters, the algorithm input and output are generated based on a predefined syntax. Figure 5 shows the second module. 
Figure 5 goes about here

In the case study, the objectives and parameters have been defined by experts, taking into account known standards (references profiles defined in legislation) and their experience in these areas of knowledge. It is possible to save the introduced parameters (Save parameters) or open others that have been already defined (Load parameters).

III. ELECTRE TRI Results - the interface of an output file is created, where alternatives are assigned to one of the three predefined categories. When the user clicks on Results (Table and Map) the classification table appears displaying the results according to the pessimistic and optimistic procedures of ELECTRE TRI. These results are added to the Attribute Table in ArcGIS, where the user can visualize the map. Figure 6 shows the third module, which also displays a count table of results, for each procedure.

Figure 6 goes about here

IV. Sensitivity Analysis - The next step is to carry out a sensitivity analysis of the results of the previous stage. The Web MC-SDSS developed allows changing the cutting level and/or weights. Furthermore, it is possible to compare the results in the both Pessimistic and Optimistic procedures to analyse and compare results. It also allows building a table with the difference in the number of categories between the pessimistic and 
optimistic procedure and get the difference map. Figure 7 shows the last module.

Figure 7 goes about here

This MC-SDSS is characterized by a single interface, with a single source of data shared by the two tools, GIS and MCDA, and the modifications by any part affect the results, for example: adding/deleting a criterion in the GIS affects MCDA results and modifying parameters of MCDA method affects results displayed. The created interface enables interactive dynamic sessions with real-time information exchange between the user and the system and facilitates communication and stakeholder's participation in decision making. A help button provides access to an explanation about the characterization and usage of the interface.

\section{Results and Discussion}

The implementation of the developed interface has led to two maps according to the optimistic and pessimistic procedures of ELECTRE TRI. It is quite obvious that the two resulting maps show a difference between the two assignment procedures (optimistic and pessimistic). Indeed, the ideas that ground the two assignment procedures are different. So it is not surprising that these assignment procedures might assign some alternatives to different categories. For more details, see Mousseau et al. (1999). In this case study, the outcome obtained by the pessimistic procedure provides a better match to the results expected by experts. 
The map represented in Figure 8 relating to the distribution of the classification of farms regarding Environmental Sustainability has been obtained by using MC-SDSS ELECTRE TRI in ArcGIS, considering the pessimistic procedure.

Figure 8 goes about here

The outcome assignment obtained by pessimistic procedure corresponds to the knowledge of real situation and matches well the results expected by the experts involved: concerning environmental sustainability it was verified that the majority of dairy farms are classified as Environmentally Not Sustainable. This fact is associated with a large concentration of farms, the poor conception of the most dairy farms, the insufficient storage capacity of manure, the misuse of equipment and methods of spreading in the soil and waterways that result in excess of incorporation of nitrogen as well as production of greenhouse gases and unpleasant odors, among other problems.

This Web MC-SDSS permits development of a Sensitivity Analysis in order to verify the robustness of the results. The main purpose in sensitivity analysis is to determine how the sorting is affected by changes in some decision maker's parameters. In this Web MCSDSS it is possible to compare the results in the Pessimistic and Optimistic procedures before and after a change in the weights and/or cutting level (if user wants to change a larger number of parameters it is better to reformulate them in ELECTRE TRI "Parameters" module) and obtain a difference map between these procedures.

\section{Conclusions}

Spatial and multicriteria aspects of the studied problem led us to develop a spatial decision support system. This system incorporates ELECTRE TRI method into ArcGIS 
9.3 of ESRI. The power of this method lies in the aggregation mode of decision-maker performances and the assignment of the potential alternatives to predefined categories. The developed system is of special importance insofar as it integrates GIS functionalities and MCDA methods in a single framework.

This paper presents a tool that integrates GIS and MCDA. GIS was used as the core of the integrated system and the MCDA models were integrated to the GIS using the programming facilities provided by the GIS software. The developed ELECTRE TRI in ArcGIS, VBA macro integrates all the components of a fully-integrated system: geographical data management and analysis tools, MCDA models and user interface. It is a user-friendly interface for configuration, prediction, visualization and analysis of the model outcomes in the same environment and thereby allowing an evaluation process which is uniform, transparent and demands less technical effort from decision makers. The exploitation of graphical display potentialities of this system provides the decision maker with information increasingly richer and easier to grasp. With GIS, data may be available in a format which will be easily interpreted, can be interactively displayed, is ready to digital processing and can be easily updated. The design and implementation of ELECTRE TRI in ArcGIS is an innovative conceptual framework for application of MCDA in spatial problems, with recourse to the Algorithm Server for ELECTRE TRI method application.

Considering the case study, one notes the worrying situation in which many farms in the EDM Region are found regarding their environmental sustainability. The interface allows analysing the geographical distribution of the environmental sustainability classification of dairy farms. Overall results show that MC-SDSS represents valuable decision support tools by providing a platform for the integration of information, models and methods necessary to assess the environmental sustainability of dairy farms. 
This MC-SDSS can be easily adapted to other applications in many areas and other MCDA Algorithm Servers.

This approach, however, still presents the following limitations: the centralized processing system requires an internet connection at least to initialize the server and to obtain the results; and the developed integration may no longer work if there are changes in the communication protocol or if a particular method is no longer available on the server. However, this is compensated by the gains in computer performance and the avoided time costs in code programming and debugging a MCDA method that others have already developed and optimized.

In the future, this research can be extended to the application of other MCDA methods by: (i) using the communication protocol of algorithm server; (ii) inserting methods for eliciting the parameters of MCDA method chosen (Figueira and Roy, 2002; Dias et al., 2002); (iii) extending to other real problems to assess sustainability (or other context). This methodology can also be extended to group decision-making domain by considering a group opinion and web-collaborative service. The current last version of ArcGIS (version10) includes compatibility for VBA, but ESRI announced the end of the support for VBA in ArcGIS Desktop in future versions. In this case the VBA code developed can be migrated to .NET or re-written in Python language (the new programming language available to customize and extend ArcGIS).

\section{References}

Abel, D. J., Kilby, P. J., Davis, J. R., 1994. The systems integration problem. International Journal of Geographic Information Systems 8, 1-12.

Antunes, P., Karadzic, V., Santos R., Beça P., Osann, A., 2011. Participatory multi-criteria analysis of irrigation management alternatives: the case of the Caia irrigation district, Portugal. International Journal of Agricultural Sustainability, 9(2): 334-349. 
Ascough II, J. C., Rector, H. D., Hoag, D. L. et al., 2002. Multicriteria spatial decision support systems: overview, applications, and future research directions. In: Conference on Integrated Assessment and decision Support, Switzerland. International Environmental Modelling and Software Society 3, 175-180.

Aydin, N.Y., Kentel, E., Duzgun S., 2010. GIS-based environmental assessment of wind energy systems for spatial planning: A case study from Western Turkey. Renewable and Sustainable Energy Reviews 14, 364-373.

Boggia, A., Greco S., Massei, G., 2011. Implementation of Multicriteria Modules in a Geographic Information System. 74rd Meeting of the European Working Group Multiple Criteria Decision Aiding (MCDA'74), HEIG-VD, Yverdon, Switzerland.

Boroushaki, S., Malczewski, J., 2008. Implementing an extension of the analytical hierarchy process using ordered weighted averaging operators with fuzzy quantifiers in ArcGIS. Computers and Geosciences 34(4), 399-410.

Boroushaki, S., Malczewski, J., 2010. ParcitipatoryGIS.com: A WebGIS-based collaborative multicriteria decision analysis. Journal of the Urban and Regional Information Systems Association 22(1): 23-32

Carver, S. J., 1991. Integrating multicriteria evaluation with geographical information systems. International Journal of Geographical Information Systems 5(3), 321-339.

Carver, S., 1999. Developing Web-based GIS/MCE: Improving access to data and spatial decision support tools. In J. C. Thill, Ed., Spatial multicriteria decision-making and analysis. Aldershot, England: Ashgate: 49-75.

Chakhar, S., Martel, J.M., 2003. Enhancing geographical information systems capabilities with multicriteria evaluation functions. Journal of Geographic Information and Decision Analysis 7, 47-71.

Chakhar, S., Mousseau, V., 2007. Multicriteria Spatial Decision Support Systems. In Shashi Shekhar and Hui Xiong, editors, Encyclopedia of Geographical Information Science, 753-758. Springer.

Chakhar, S., Mousseau, V., 2008. Spatial multicriteria decision making. In S. Shekhar \& H. Xiong (Eds.), Encyclopedia of GIS, 747-753. New York: Springer.

Chakhar, S., Mousseau, V., 2009. Generation of spatial decision alternatives based on a planar subdivision of the study area. In Yetongnon, K., Chbeir, R., Dipanda, A. (Eds.), Advanced Internet Based Systems and Applications, 137-148.

Chen, K., Blong, R., Jacobson, C., 2001. MCE-RISK: Integrating multicriteria evaluation and GIS for risk decision-making in natural hazards. Environmental Modelling and Software 16, 387-397.

Common GIS, 2013: http://www.esds.ac.uk/international/support/commongis.asp

Dantsis, T., Douma, C., Giourga, C., Loumou, A., Polychronaki, E.A., 2010. A methodological approach to assess and compare the sustainability level of agricultural plant production systems. Ecological Indicators, 10: 256-263.

DECERNS SDSS, 2013: http://www.decerns.com

Dias, L., Mousseau, V., Figueira, J., Clímaco, J., 2002. An aggregation/disaggregation approach to obtain robust conclusions with ELECTRE TRI. European Journal of Operational Research 138, 332-348. 79-81.

Dragićević, S., 2004. The potential of Web-based GIS. Journal of Geographical Systems 6: 
Eastman, J. R., 1999. Multicriteria evaluation and GIS; in Longley, P., Geographical Information System, 493-502. New York, John Wiley, Sons.

Eldrandaly, K., Eldin, N., Sui D., Shouman, M., Nawara, G., 2005. Integrating GIS and MCDM Using COM Technology. The International Arab Journal of Information Technology 2(2).

ESRI ArcScripts, 2013: http://arcscripts.esri.com

Ferretti V., 2011. A Multicriteria Spatial Decision Support System Development for Siting a Landfill in the Province of Torino (Italy). Journal of Multicriteria Decision Analysis 18, 231252.

Figueira, J., Roy, B., 2002. Determining the weights of criteria in the ELECTRE type methods with a revised Simos' procedure. European Journal of Operational Research 139, $317-$ 326.

Figueira, J., Mousseau, V., Roy, B., 2005. Electre Methods. In: Figueira, J.; Greco, S.; Ehrgott, M. Multiple Criteria Decision Analysis: State of the Art Surveys. New York: Springer, Cap. 4.

Figueira, J.R., Greco S., Roy B., Słowinski R., 2010. ELECTRE methods: Main features and recent developments. In C. Zopounidis and P. Pardalos (Eds.), Handbook of Multicriteria Analysis, Chapter 4, New York, USA: Springer.

Finlay, P. N., 1994. Introducing decision support systems. Oxford, UK Cambridge, Mass., NCC Blackwell; Blackwell Publishers.

Gilliams, S., Raymaekers, D., Muys, B., Orshoven, J. V., 2005. Comparing multiple criteria decision methods to extend a geographical information system on afforestation. Computers and Electronics in Agriculture 49, 142-158.'

Gómez-Limón, J. A., Riesgo, L., 2009. Alternative Approaches to the construction of a composite indicator of agricultural sustainability: An application to irrigated agriculture in the Duero basin in Spain. Journal of Environmental Management, 90: 3345-3362.

Goodchild, M.F., 1992. Geographical information science. International Journal Geographical Information Systems 6(1), 31-45.

GRASS GIS, 2013: http://grass.osgeo.org

Hall, B., Leahy M. G., 2006. Internet-based spatial decision support using open source tools. In S. Balram and S. Dragićević, Eds., Collaborative geographic information systems. Hershey: Idea Group Publishing, 237-62.

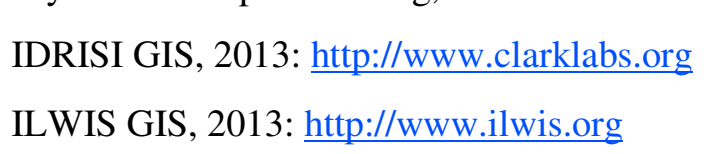

Jankowski, P., Richard, L., 1994. Integration of GIS-based suitability analysis and multicriteria evaluation in a spatial decision support system for route selection. Environment and Planning B 21(3), 326-339.

Jankowski, P., 1995. Integrating geographical information systems and multiple criteria decision making methods. International Journal of Geographical Information Science 9, 251273.

Janssen, R., Rietveld P., 1990. Multicriteria analysis and geographical information systems: An application to agriculture land-use in Netherlands. In: H.J. Scholten, and J.C.H. Stillwell (eds.) Geographical information systems for urban and regional planning, pp. 129-139. Dorchecht: Kluwer Academic Publishers. 
Joerin F., Musy A., 2000. Land management with GIS and multicriteria analysis. International Transactions in Operational Research 7, 67-78.

Joerin, F., Thériault, M., Musy, A., 2001. Using GIS and outranking multicriteria analysis for land-use suitability assessment. International Journal Geographical Information Science $15(2), 153-174$

Karnatak, H. C., Saran S., Bhatia K., Roy P. S., 2007. Multicriteria spatial decision analysis in Web GIS environment. Geoinformatica 11(4): 407-29.

Laaribi, A., Chevallier J. J. and Martel M., 1996. A spatial Decisions Aid: A Multicriterion Evaluation Approach. Computers. Environment and Urban Systems 20 (6), 351-366.

Lebacq, L., Baret, P.V., Stilmant, D. 2013. Sustainability indicators for livestock farming. A review. Agronomy for Sustainable Development, 33:311-327.

Malczewski, J., 1999. GIS and multicriteria decision analysis. New York: John Wiley \& Sons.

Malczewski, J., Chapman, T., Flegel, C., Walters, D., Shrubsole, D., Healy, M.A., 2003. GIS multicriteria evaluation with ordered weighted averaging (OWA): case study of developing watershed management strategies. Environment and Planning A 35, 1769-1784.

Malczewski, J., 2006. Review Article GIS-based multicriteria decision analysis: a survey of the literature. International Journal of Geographical Information Science 20(7), 703-726.

Malczewski, J., 2010. Multiple Criteria Decision Analysis and Geographic Information Systems. In: J. Figueira, S. Greco and M. Ehrgott (eds.) Trends in Multiple Criteria Decision Analysis, 369-395. Springer, New York.

Marinoni, O., 2004. Implementation of the analytical hierarchy process with VBA in ArcGIS. Computers and Geosciences 30, 637-646.

Mendas, A., Delali, A. (2012). Integration of MultiCriteria Decision Analysis in GIS to develop land suitability for agriculture: Application to durum wheat cultivation in the region of Mleta in Algeria. Computers and Electronics in Agriculture, 83, 117-126

Menegolo, L., Peekham, R. J., 1996. A fully integrated tool for site planning using multi criteria evaluation techniques within a GIS. In M. Rumor, R. McMillan, H. F. L. Ottens, Eds., Geographical information. Amsterdam: IOSA Press, 621-30.

Mousseau, V., Slowinski, R., 1998. Inferring an ELECTRE-TRI model from assignment examples. Journal of Global Optimization 12(2), 157-174.

Mousseau, V., Slowinski, R., Zielniewicz, P., 1999. ELECTRE Tri 2.0a, Methodological guide and user's manual. Document no. 111 of LAMSADE.

Mousseau, V., Dias, L., 2004. Valued outranking relations in ELECTRE providing manageable disaggregation procedures. European Journal of Operational Research 156, 467482.

Parks, B. O., 1993. The need for integration. In: Goodchild, M.F., Parks, B. O., Steyarert, L.T. (Editor), Environmental Modeling with GIS, 31 - 34. New York, Oxford University Press.

Pereira, J. M.C., Duckstein, L., 1993. A multiple criteria decison-making approach to GISbased land suitability evaluation. International Journal of Geographical Information Systems 7(5), 407-424.

POBLPEMD, 2007. Plano de Ordenamento da Bacia Leiteira Primária do Entre Douro e Minho. Direção Regional de Agricultura de Entre Douro e Minho ('Entre Douro e Minho's Regional Development Plan for Dairy Farming'); Escola Superior Agrária do Instituto 
Politécnico de Viana do Castelo; Instituto para o Desenvolvimento Agrário da Região Norte; Universidade do Porto - CIBIO. 153 pp.

QUANTUM GIS, 2013: http://www.quantum.com

Raju, K.S., Duckstein, L., Arondel, C., 2000. Multicriterion Analysis for Sustainable Water Resources Planning: A Case Study in Spain. Water Resources Management, 14: 435-456.

Rao, M., G. Fan, Thomas J., Cherian G., Chudiwale V., Awawdeh M., 2007. A Web-based GIS decision support system for managing and planning USDA's Conservation Reserve Program (CRP). Environmental Modelling and Software 22(9): 1,270-80.

Rinner, C., J. Malczewski , J., 2002. Web-Enabled Spatial Decision Analysis Using Ordered Weighted Averaging (OWA). Journal of Geographical Systems 4(4), 385-403.

Rinner, C., 2003. Web-based Spatial Decision Support: Status and Research Directions. Journal of Geographic Information and Decision Analysis 7 (1), 14-31.

Roy B. e Bouyssou, D., 1993. Aide multicritère à la décision: méthodes et cas, Economica, Paris.

Roy, B., 1996. Multicriteria Methodology for Decision Aiding. Kluwer Academic Publishers.

Santé-Riveira, I., Crecente-Maseda, R., Miranda-Barrósa, D., 2008. GIS-based planning support system for rural land-use allocation. Computers and Electronics in Agriculture 63 (2), 257-273.

Santos, J.C.S.M., 2011. Viabilidad de las explotaciones lecheras en un escenario de desconexión del apoyo y condicionalidad: Un estudio de caso en el noroeste de Portugal. Ph.D. Dissertation, Universidad Politécnica de Madrid, Escuela Técnica Superior de Ingenieros Agrónomos.

Sharifi, M.A., Retsios, V., 2004. Site selection for waste disposal through spatial multiple criteria decision analysis. Journal of Telecommunications and Information Technology 3, 1- 11.

Simão, A., Densham P. J., Haklay M., 2009. Web-based GIS for collaborative planning and public participation: An application to the strategic planning of wind farm sites. Journal of Environmental Management 90(6), 2027-40.

Sikder, I. U., Gangopadhyay A., 2002. Design and implementation of a Web-based collaborative spatial decision support system: Organizational and managerial implications. Information Resources Management Journal 15(4): 33-47.

Sobrie, O., 2011. Implementation of the ELECTRE TRI multicriteria method in an Open Source Geographical Information System. 73rd Meeting of the European Working Group Multiple Criteria Decision Aiding (MCDA'73), University of Corsica.

Sobrie, O., Pirlot, M., 2012. Implementation of the ELECTRE TRI in an Open Source GIS. European Working Group "Multiple Criteria Decision Aiding" Newsletter. Series 3, n 26, Fall 2012.

Sobrie, O., Pirlot, M., Joerin, F., 2013. Intégration de la method d'aide à la décision ELECTRE TRI dans un système d'information géographique open source. Revue Internationale de Géomatique 23(1): 13-38.

Sugumaran, R., Degroote, J., 2011. Spatial Decision Support Systems- Principles and practices. Taylor and Francis Group.

Van Calker, K., Berentsen, P., Romero, C., Giesen, G., Huirne, R., 2006. Development and application of multi-attribute sustainability function for Dutch dairy farming systems. Ecological Economics, 57: 640-658. 
Van der Meulen, G. G., 1992. Geographical information and decision support system. Computers, Environment and Urban Systems 16, 187-193.

Vogel, R., 2008. A Software Framework for GIS-based Multiple Criteria Evaluation of Land Suitability. 11th AGILE International Conference on Geographic Information Science, University of Girona, Spain.

Walsh, M. R., 1992, "Toward spatial decision support systems in water resources". Journal of Water Resources Planning and Management. 109 (2): 158-169.

Worrall L., 1991. Spatial analysis and spatial policy using geographic information systems. Belhaven Press, London (UK).

Yu, W., 1992. ELECTRE TRI: Aspects méthodologiques et manuel d'utilisation. Document du LAMSADE No. 74, Université Paris-Dauphine.

Zhao, L., Garner, B. J., 2001. Developing GIS Tools to Integrate MCDM models for the analysis of bank branch closures. In: 6th International Conference on GeoComputation, University of Queens land, Brisbane, Australia.

Zhu, X., Dale, A. P., 2001. JavaAHP: A Web-based decision analysis tool for natural resource and environmental management. Environmental Modelling and Software 16(3): 25162. 
Tables

\begin{tabular}{|c|l|c|}
\hline Environmental Criteria & Objective & Name \\
\hline Storage Capacity of Manure & Maximize & STORCA \\
\hline Area of Application of Manure in the Soil & Minimize & AREAMA \\
\hline Incorporation in Excess of Nitrogen in the Farm & Minimize & INCORPN \\
\hline Total Production of Greenhouse Gases & Minimize & PRODCO2 \\
\hline Number of Storage Structures Near Water Lines & Minimize & NEARWAT \\
\hline Individualized Collection of Rainwater & Maximize & ICOLRWAT \\
\hline Animal Well-being & Maximize & ANIMWB \\
\hline
\end{tabular}

Table 1: Environmental Criteria and their objectives 
FIGURES

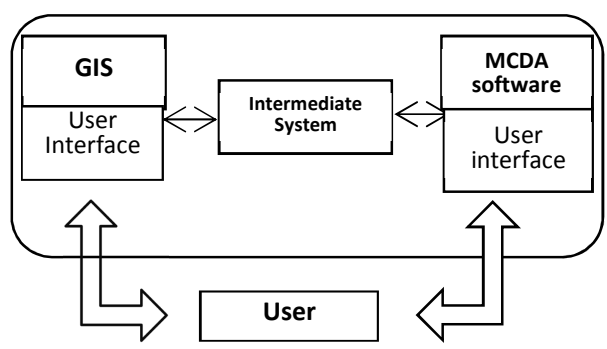

(a)

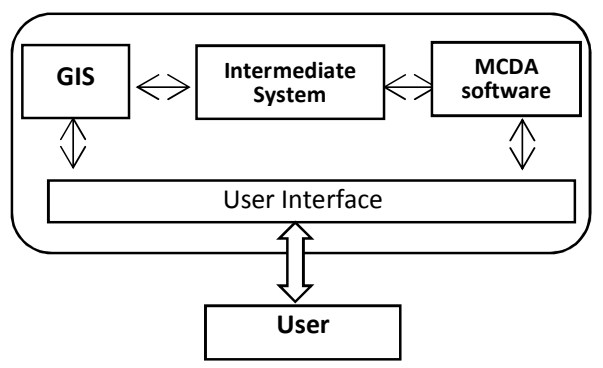

(b)

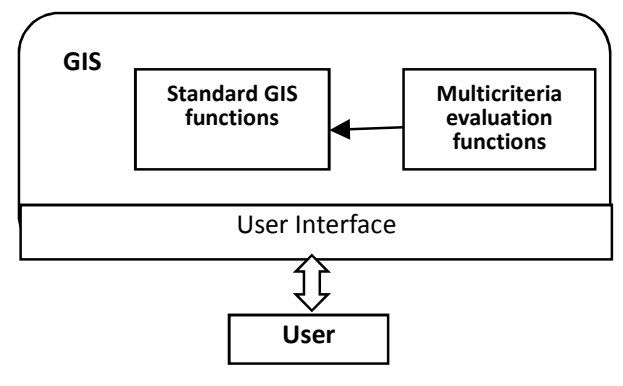

(c)

Figure 1: Scheme modes of integration GIS and MCDA: (a) loose, (b) tight and (c) full (Chakhar e Mousseau, 2007)

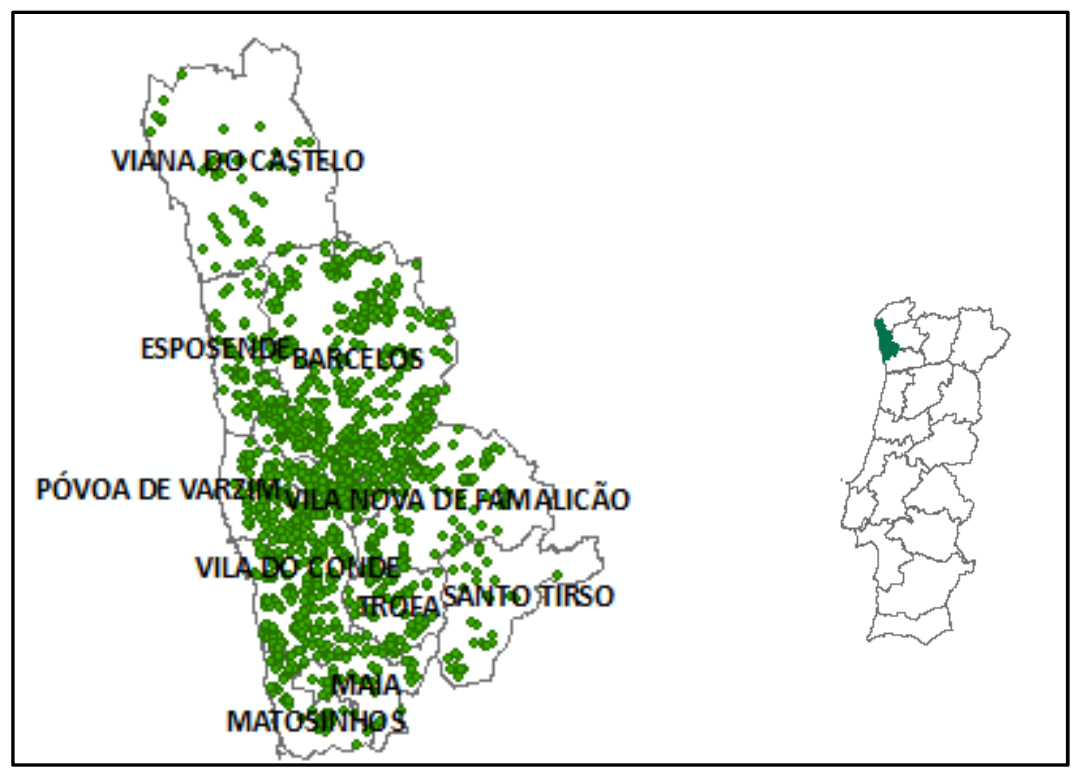

Figure 2: Map spatial distribution of dairy farms. 


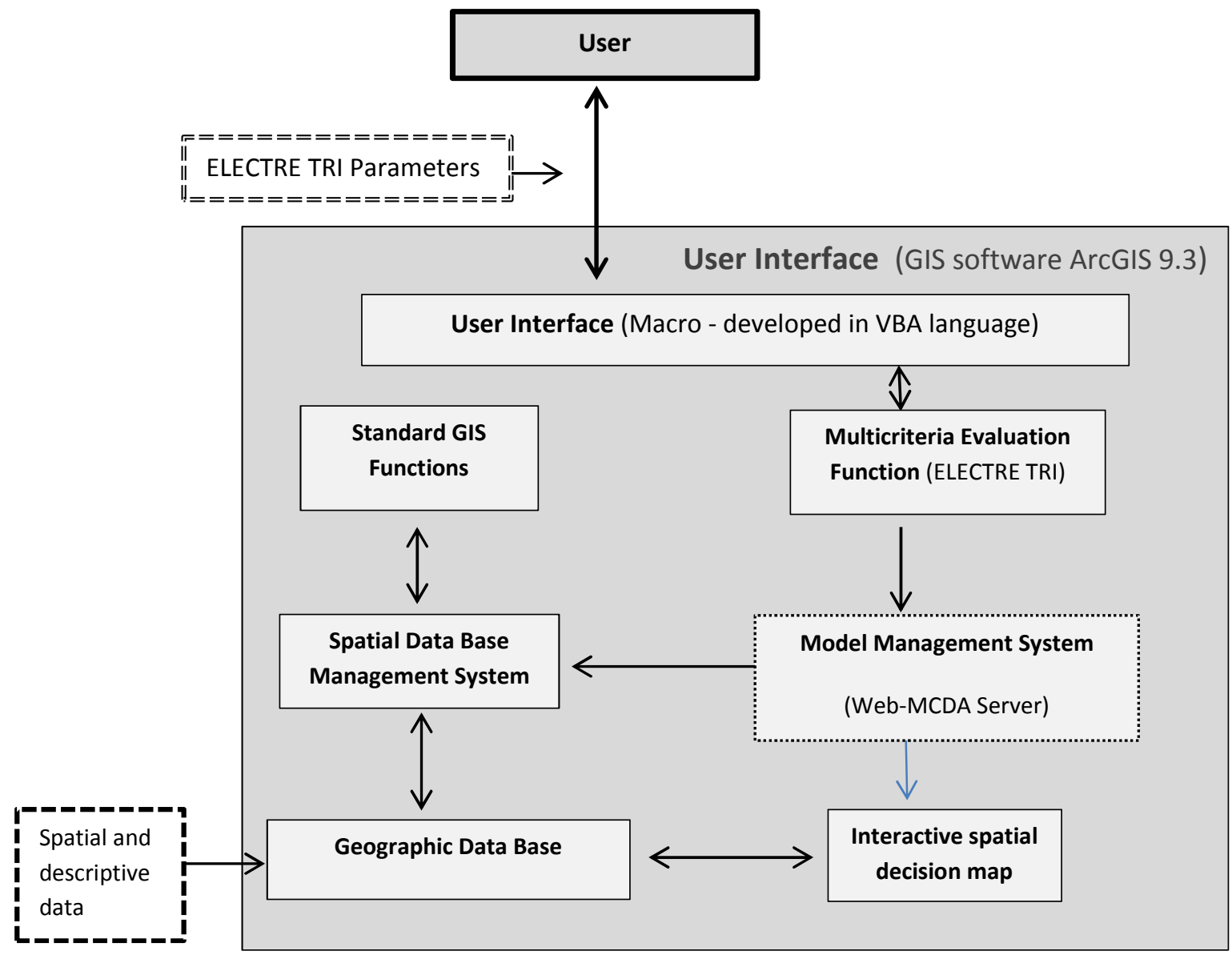

Figure 3: Architecture of Web MC-SDSS. 


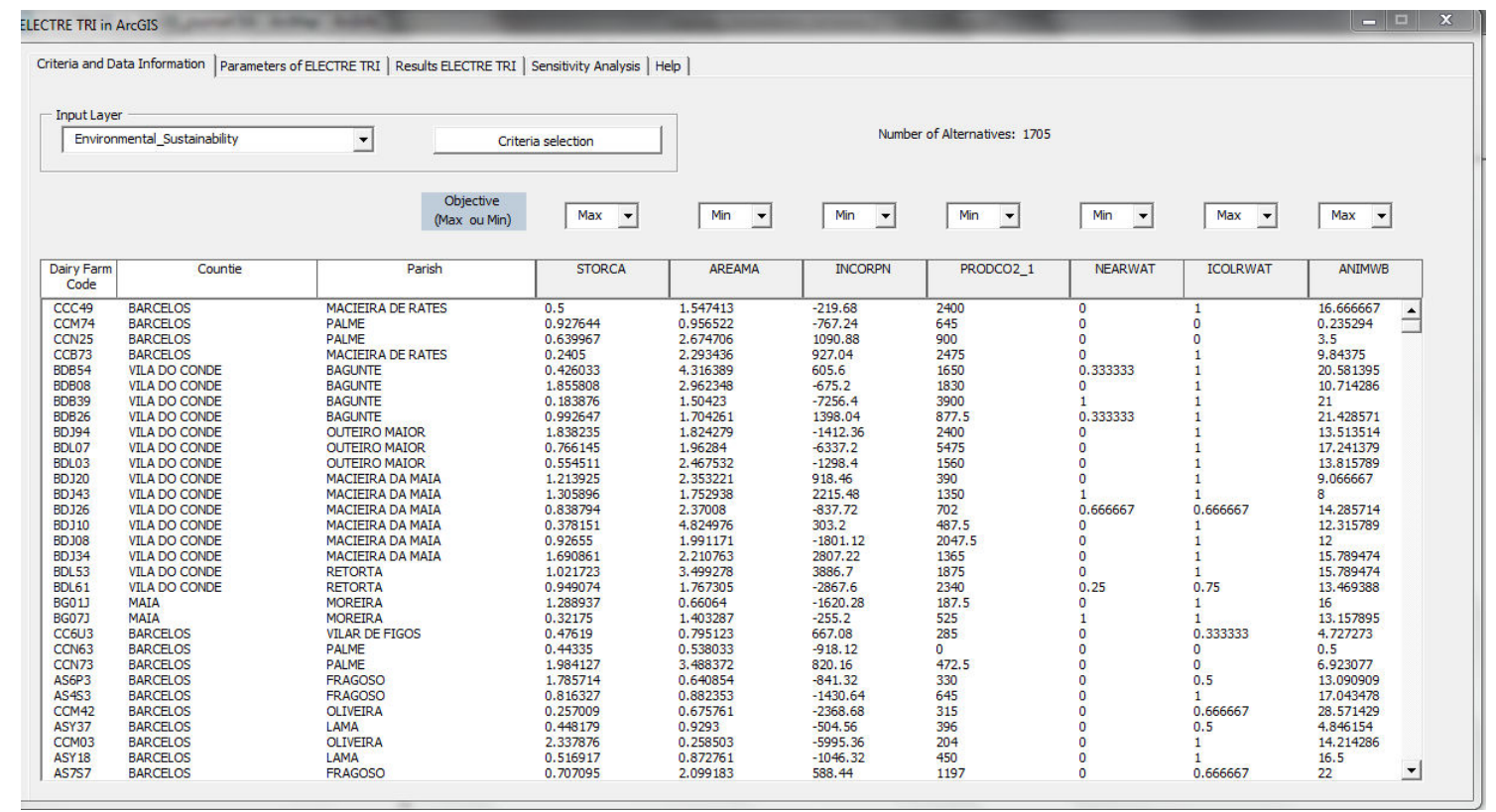

Figure 4: First module: Criteria and Information.

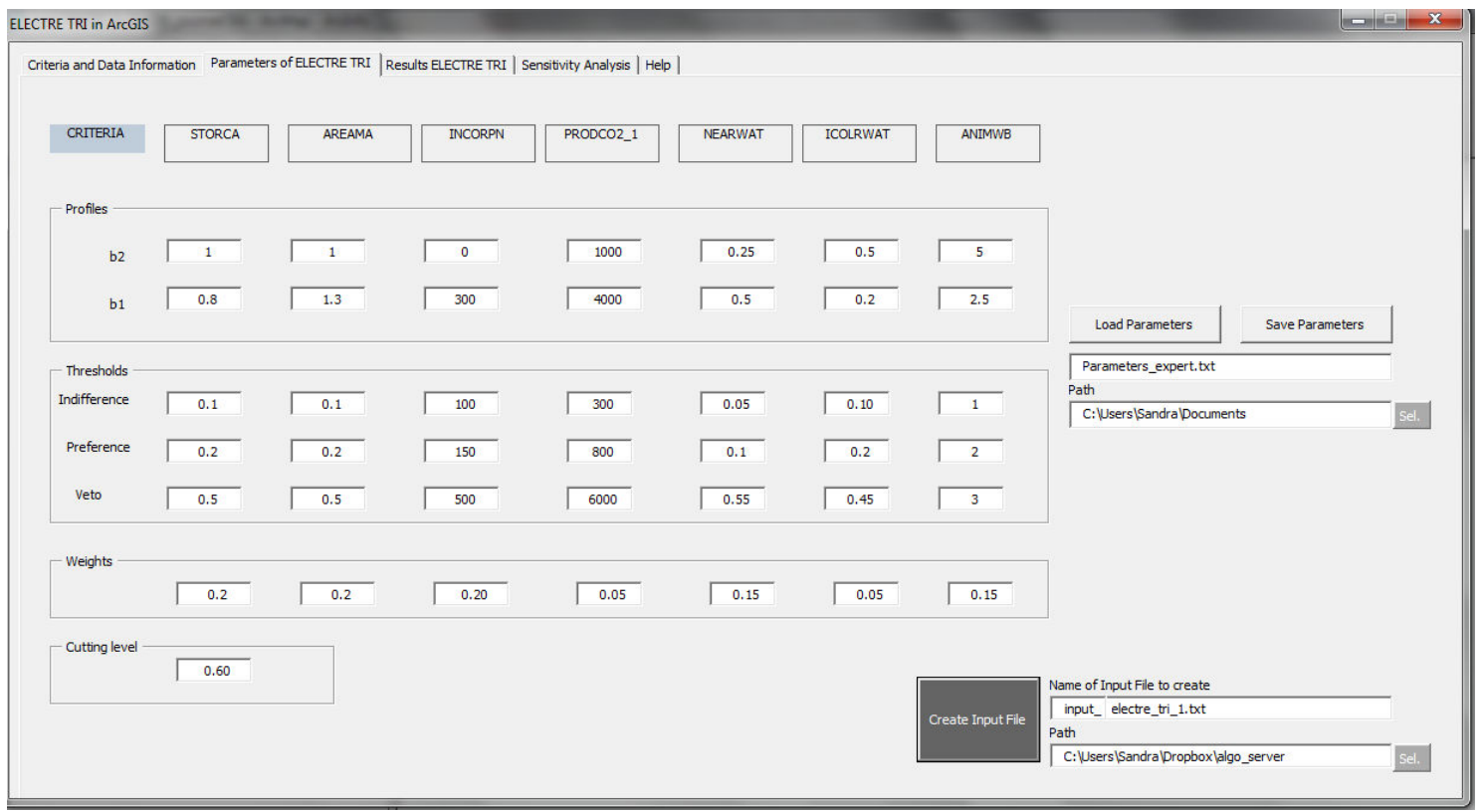

Figure 5: Second module: Parameters of ELECTRE TRI. 


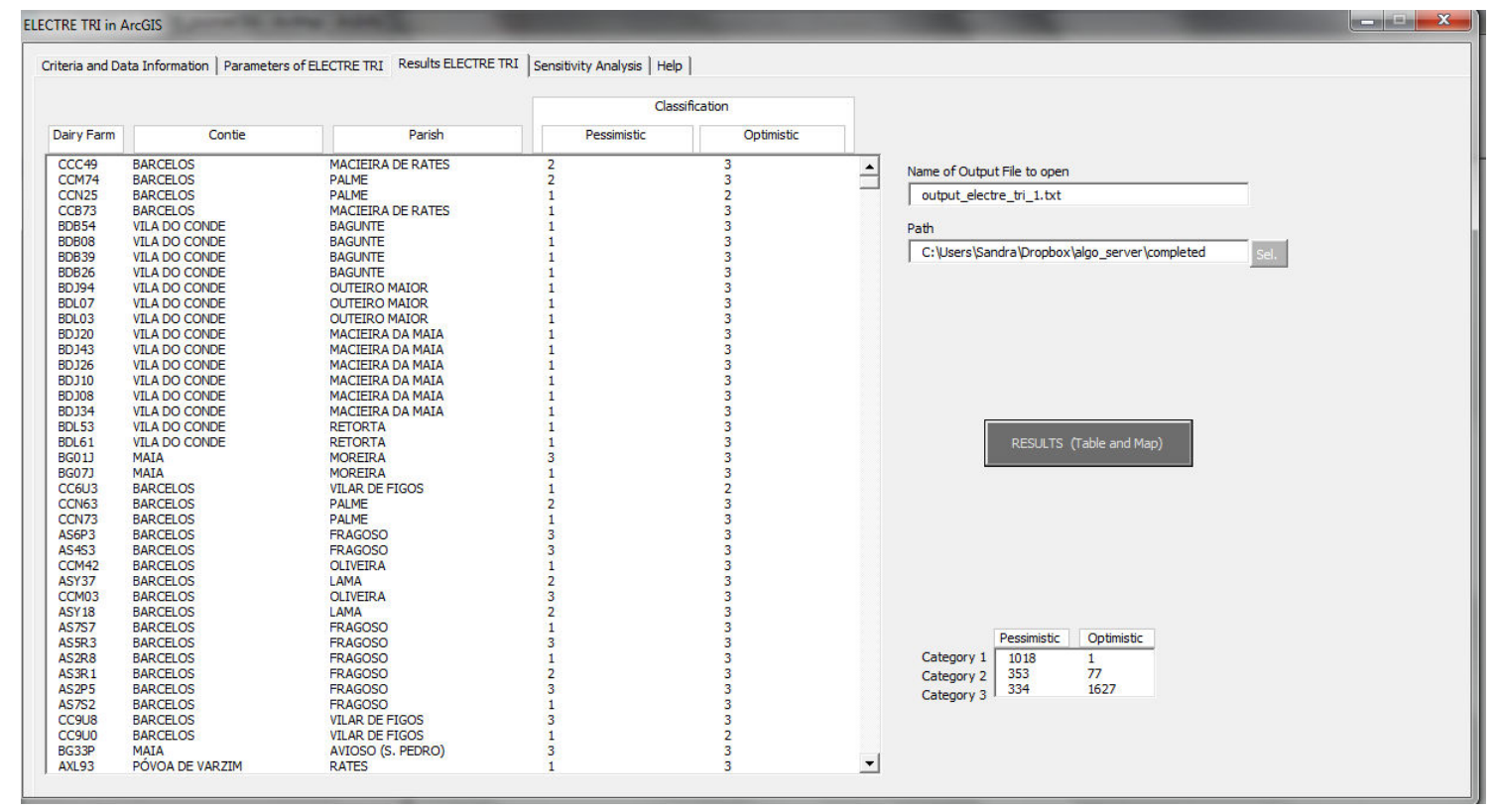

Figure 6: Third module: Results of ELECTRE TRI

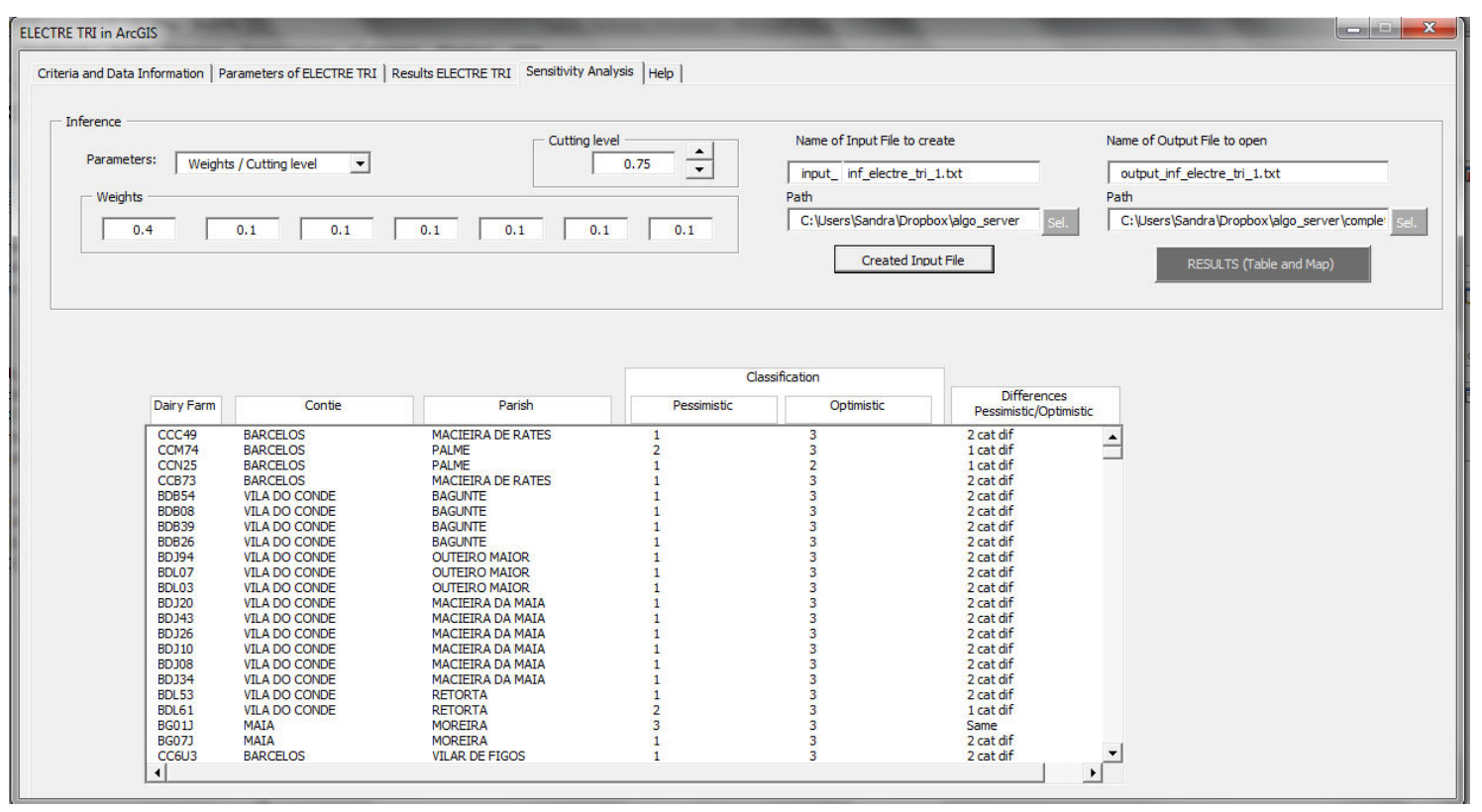

Figure 7: Fourth module: Sensitivity Analysis 


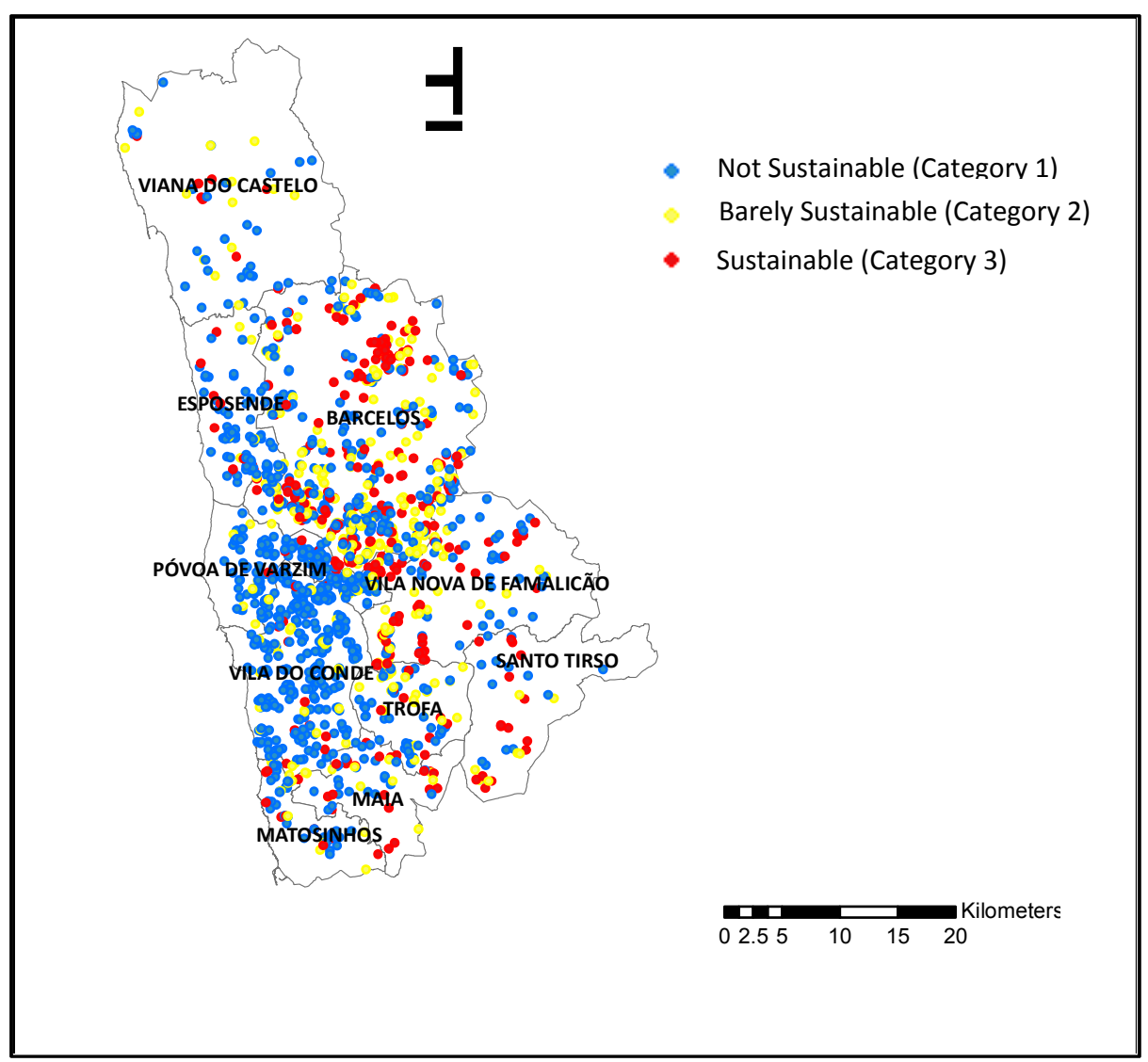

Figure 8: Distribution of environmental sustainability classification of dairy farms (in pessimistic procedure) 